\section{Estudo mineral de plantas medicinais}

\section{Maria de Fátima Gomes Lopes; Maria Mozarina Beserra Almeida; Célia Maria Diógenes Nogueira; Noélia Maria Tavares de Morais; Carlos Emanuel de Carvalho Magalhães*}

Departamento de Química Analítica, Físico-Química, Universidade Federal do Ceará, Campus do Pici s/n Bloco 940, 60455-760, Fortaleza, CE

cecmagal@ufc.br

\begin{abstract}
Determinations of $\mathrm{Ca}, \mathrm{Cu}, \mathrm{Fe}, \mathrm{Mg}, \mathrm{Mn}$ and $\mathrm{Zn}$ were evaluated in five different samples of medicinal plant leaves. Atomic absorption spectrometry was applied to the metals quantification. Except for $\mathrm{Fe}$ in Artemisia vulgaris $\mathrm{L}$, significant levels of these elements were found in all investigated plant as compared to other vegetables which are abundant concerning that mineral content.
\end{abstract}

$\mathrm{O}$ uso de vegetais tem se difundido largamente nos últimos anos no tratamento fitoterápico de muitas doenças ${ }^{1}$. Por esta razão, existe um interesse crescente sobre o estudo da composição desses vegetais, tanto para constituintes orgânicos como para os inorgânicos ${ }^{2}$. Nesse sentido, amostras de aroeira da praia (Schinus terebinthifolius Raddi.), artemísia (Artemisia vulgaris L.), cainca (Chiococca brachiata Ruiz \& Pav.) cambará (Lantana camara L.) e poejo (Mentha pulegium L.) foram analisadas com o propósito de se determinar os teores de umidade, cinzas totais, sílica e elementos minerais $(\mathrm{Ca}, \mathrm{Cu}, \mathrm{Fe}$, $\mathrm{Mg}, \mathrm{Mn}$ e $\mathrm{Zn}$ ) reconhecidamente importantes na nutrição humana.

Todas as análises foram realizadas em triplicata e o coeficiente de variação entre as medidas foi inferior a $5 \%$. Os resultados obtidos para as determinações dos teores de umidade, cinzas totais e sílica encontram-se na Tabela 1. As plantas analisadas apresentaram teores semelhantes de sílica e cinzas totais. Com relação à umidade, camará e aroeira da praia mostraram uma maior capacidade de absorver água, em comparação às demais espécies em questão.

Tabela 1. Teores de umidade, cinzas totais e sílica nas plantas medicinais estudadas

\begin{tabular}{l|l|l|l}
\hline Vegetal & Umidade (\%) & Cinzas totais (\%) & Sílica (\%) \\
\hline Aroeira & 36,1 & 8,1 & 0,2 \\
\hline Artemísia & 22,0 & 10,4 & 0,2 \\
\hline Cainca & 12,5 & 10,3 & 0,3 \\
\hline Camará & 33,5 & 9,2 & 0,3 \\
\hline Poejo & 10,8 & 10,6 & 0,4 \\
\hline
\end{tabular}

Rev. Bras. Farmacogn., v. 12, supl., p. 115-116, 2002.

ISSN: 0102-695X
As concentrações dos metais estão sumarizadas na Tabela 2. Nota-se uma grande variação de teores de todos os elementos presentes nos cinco vegetais. De um modo geral, artemísia apresentou os níveis mais baixos dos constituintes analisados, com exceção do Mg. Destacam-se a aroeira da praia pelos teores relativamente elevados de $\mathrm{Ca}$ e $\mathrm{Fe}$, bem como o poejo, o qual exibiu teores razoavelmente elevados de Fe, Zn e $\mathrm{Cu}$, sendo este último, um elemento considerado potencialmente tóxico. Teores significativos desses metais foram encontrados em todos os vegetais estudados com exceção do Fe na artemísia, quando comparados a outros vegetais que são reconhecidamente ricos nos constituintes em questão ${ }^{3,4}$.

Tabela 2. Determinação de metais $(\mathrm{mg} / 100 \mathrm{~g})$ nas plantas medicinais estudadas

\begin{tabular}{l|l|l|l|l|l|l}
\hline Vegetal & $\mathrm{Ca}$ & $\mathrm{Cu}$ & $\mathrm{Fe}$ & $\mathrm{Mg}$ & $\mathrm{Mn}$ & $\mathrm{Zn}$ \\
\hline Aroeira & 2020 & 1,11 & 6,79 & 97,9 & 3,04 & 2,26 \\
\hline Artemísia & 493 & 0,07 & $<\mathrm{L} . \mathrm{D}$. & 153 & 0,93 & 0,43 \\
\hline Cainca & 976 & 2,66 & 3,53 & 128 & 2,05 & 6,07 \\
\hline Camará & 1032 & 2,12 & 4,90 & 88,29 & 2,70 & 0,76 \\
\hline Poejo & 890 & 6,25 & 7,91 & 287 & 4,74 & 13,77 \\
\hline
\end{tabular}

\section{Material e Métodos}

Empregaram-se os métodos oficiais para a decomposição e análise das amostras ${ }^{5,6}$. As folhas das plantas foram coletadas no Horto do Laboratório de Produtos Naturais da Universidade Federal do Ceará, em seguida, picotadas, lavadas com água de torneira, água destilada e secas à temperatura ambiente.

Os teores de umidade, cinzas totais e sílica foram determinados gravimetricamente. Para a determinação da umidade, cerca de $10 \mathrm{~g}$ de material foi pesado para depois ser seco em estufa Fanem a $105^{\circ} \mathrm{C}$ durante $2 \mathrm{~h}$. A seguir, o material foi resfriado e pesado até se obter um peso constante, dentro de uma precisão de $0,1 \mathrm{mg}$. $\mathrm{O}$ teor de cinzas totais foi quantificado através da calcinação de $10 \mathrm{~g}$ de material seco em forno Mufla Quimis a $580-600^{\circ} \mathrm{C}$ por $12 \mathrm{~h}$. Para se avaliar a concentração de sílica nas amostras, a fração não solúvel das cinzas totais foi retida em papel de filtro quantitativo (faixa preta) e, posteriormente, calcinada a $900{ }^{\circ} \mathrm{C}$ durante $6 \mathrm{~h}$, sendo pesada após resfriamento em dessecador.

As cinzas foram solubilizadas em ácido nítrico $3 \mathrm{~mol}$, submetidas à evaporação até quase secura e transferidas quantitativamente para balões de $100 \mathrm{ml}$. Quando necessário, novas diluições foram realizadas adequadamente, para que os teores medidos ocorressem dentro da faixa de linearidade de concentração para cada elemento, possibilitando a quantificação dos mesmos em todas as amostras (Tabela 2). Para este propósito, empregou-se a espectrometria de absorção atômica com chama (Perkin Elmer, modelo Analyst 300) nas condições experimentais recomendadas pelo fabricante. Utilizou-se 
lâmpada de deutério como corretor da absorção de fundo e nitrato de lantânio como supressor de interferentes na determinação de cálcio. As medidas de $\mathrm{Ca}, \mathrm{Cu}, \mathrm{Fe}, \mathrm{Mg}, \mathrm{Mn}$ e $\mathrm{Zn}$ foram realizadas nos comprimentos de onda, 422,$7 ; 324,7 ; 248,3 ; 285,2$; 279,5 e $213,9 \mathrm{~nm}$, respectivamente.

\section{Referências}

${ }^{1}$ Matos F J A. Farmácias Vivas, Edições UFC. Fortaleza. 1994, $179 \mathrm{p}$

${ }^{2}$ Jain N, Shahoo R K, Sondhi S M. Analysis for Mineral Elements of Some Medicinal Plants. Indian Drugs. 1992; 29 (4): 187-190

${ }^{3}$ Morais NMT, Nogueira CMD, Lopes MFG, Vasconcelos NMS, Sá MJHC. Estudo Inorgânico Analítico de Plantas Medicinais. Anais Assoc. Bras. Quím. 1995; 44 (4): 14-19

${ }^{4}$ Nogueira CMD, Lopes MFG, Morais NMT, Almeida MB, Vasconcelos NMS, Sá MJHC. Determinação de Elementos Minerais em Plantas Medicinais. Anais Assoc. Bras. Quím. 1998; 47 (1): $22-24$

${ }^{5}$ Association of Official analytical Chemistry - Official Methods of Analysis of the Association of Official Analytical Chemistry, $13^{\mathrm{a}}$ ed. Washington. 1980: 1018p

${ }^{6}$ do Instituto Adolfo Lutz - Normas Analíticas do Instituto Adolfo Lutz. Vol. I $3^{\mathrm{a}}$ ed. São Paulo. 1985; 533p
Dosagem de artemisinina em Artemisia annua L. por cromatografia líquida de alta eficiência com detecção por índice de refração

\author{
Vera Lúcia Garcia Rehder ${ }^{1 *}$; Marili Villa Nova Rodrigues"; \\ Adilson Sartoratto'; Mary Ann Foglio ${ }^{2}$ \\ ${ }^{1}$ Divisão de Química Orgânica e Farmacêutica do CPQBA, \\ UNICAMP, Paulínia, SP \\ ${ }^{2}$ Divisão de Fitoquímica do CPQBA, UNICAMP, Paulínia, SP \\ rehder@cpqba.unicamp.br
}

\begin{abstract}
Artemisinin is a sesquiterpene lactone used in treatment of chloroquine-resistant malaria. This paper presents high-performance liquid chromatographic assay for artemisinin in leaves of A. аппиа using differential refractometer detector and a single step of clean-up in a silica cartridge. The average of recoveries were $95 \%$ and the limit of quantification was $0,21 \%$ $\mathrm{p} / \mathrm{p}$ using $200 \mathrm{mg}$ of the leaves. This method was found to be simple, robust and relatively rapid.
\end{abstract}

A malária é a mais importante doença parasitária tropical. A estimativa mundial de ocorrência da doença é da ordem de 300 a 500 milhões de casos clínicos por ano e a mortalidade causada pela malária é superior a 1 milhão ao ano ${ }^{1}$. Até o momento, a melhor alternativa para o tratamento da malária, causada pelo P. falciparum, é a utilização dos derivados semi-sintéticos da artemisinina, uma lactona sesquiterpênica isolada das folhas de Artemisia аппиа L., que contém em sua estrutura uma função endoperóxido, a qual é atribuída sua potente atividade antimalárica ${ }^{1,2}$. A inexistência de grupos cromóforos e funcionais nas moléculas de artemisinina e derivados, dificulta sua análise, e na maioria das vezes, para facilitar sua detecção, torna-se necessária a derivatização para outra espécie. Vários métodos por cromatografia líquida de alta eficiência têm sido propostos utilizando-se diferentes detetores: detecção eletroquímica ${ }^{3}$, detecção por ultravioleta sem derivatização $0^{4}$, com derivatização pré-coluna ${ }^{5}$, com derivatização pós-coluna ${ }^{6}$.

O procedimento de limpeza da amostra foi eficiente, mostrando um cromatograma com poucos interferentes, num tempo de eluição de 10 min (Figura 1). O método foi linear na faixa entre 90 a $900 \mathrm{mg} / \mathrm{ml}$ de artemisinina e o estudo de recuperação apresentou uma recuperação média de 95,24\% com coeficiente de variação de 9,12\% (Tabela 1). 